ARTICLE

Check for updates

https://doi.org/10.1038/s41467-020-19309-4

\title{
Atomically dispersed Lewis acid sites boost 2-electron oxygen reduction activity of carbon-based catalysts
}

\author{
Qihao Yang ${ }^{1,2,8}$, Wenwen Xu (1) 1,2,8, Shun Gong ${ }^{1,3,8}$, Guokui Zheng ${ }^{1,4}$, Ziqi Tian ${ }^{1,2,5 凶}$, Yujie Wen ${ }^{6}$, \\ Luming Peng $\mathbb{1}^{6}$, Linjuan Zhang $\mathbb{1}^{7}$, Zhiyi Lu, ${ }^{1,2 凶}$ \& Liang Chen ${ }^{1,2 凶}$
}

Elucidating the structure-property relationship is crucial for the design of advanced electrocatalysts towards the production of hydrogen peroxide $\left(\mathrm{H}_{2} \mathrm{O}_{2}\right)$. In this work, we theoretically and experimentally discovered that atomically dispersed Lewis acid sites (octahedral $\mathrm{M}-\mathrm{O}$ species, $M=$ aluminum ( $\mathrm{Al}$ ), gallium (Ga)) regulate the electronic structure of adjacent carbon catalyst sites. Density functional theory calculation predicts that the octahedral $\mathrm{M}-\mathrm{O}$ with strong Lewis acidity regulates the electronic distribution of the adjacent carbon site and thus optimizes the adsorption and desorption strength of reaction intermediate $\left({ }^{\star} \mathrm{OOH}\right)$. Experimentally, the optimal catalyst (oxygen-rich carbon with atomically dispersed Al, denoted as $\mathrm{O}-\mathrm{C}(\mathrm{Al})$ ) with the strongest Lewis acidity exhibited excellent onset potential ( 0.822 and $0.526 \mathrm{~V}$ versus reversible hydrogen electrode at $0.1 \mathrm{~mA} \mathrm{~cm}-2 \mathrm{H}_{2} \mathrm{O}_{2}$ current in alkaline and neutral media, respectively) and high $\mathrm{H}_{2} \mathrm{O}_{2}$ selectivity over a wide voltage range. This study provides a highly efficient and low-cost electrocatalyst for electrochemical $\mathrm{H}_{2} \mathrm{O}_{2}$ production.

\footnotetext{
${ }^{1}$ Ningbo Institute of Materials Technology and Engineering, Chinese Academy of Sciences, 315201 Ningbo, Zhejiang, People's Republic of China. ${ }^{2}$ University of Chinese Academy of Sciences, 100049 Beijing, People's Republic of China. ${ }^{3}$ University of Science and Technology of China, 230026 Hefei, Anhui, People's Republic of China. ${ }^{4}$ Key Laboratory of Biomass Chemical Engineering of Ministry of Education, College of Chemical and Biological Engineering, Zhejiang University, 310027 Hangzhou, Zhejiang, People's Republic of China. ${ }^{5}$ Fujian Institute of Innovation, Chinese Academy of Sciences, 350002 Fuzhou, Fujian, People's Republic of China. ${ }^{6}$ Key Laboratory of Mesoscopic Chemistry of Ministry of Education, School of Chemistry and Chemical Engineering, Nanjing University, 210023 Nanjing, Jiangsu, People's Republic of China. ${ }^{7}$ Key Laboratory of Interfacial Physics and Technology, Shanghai Institute of Applied Physics, Chinese Academy of Sciences, 201800 Shanghai, People's Republic of China. ${ }^{8}$ These authors contributed equally: Qihao Yang, Wenwen Xu, Shun Gong.

凶email: tianziqi@nimte.ac.cn; luzhiyi@nimte.ac.cn; chenliang@nimte.ac.cn
} 
ydrogen peroxide $\left(\mathrm{H}_{2} \mathrm{O}_{2}\right)$ is a ubiquitous and environmental friendly oxidant that has seen extensive use for over a century, particularly in applications for bacteria/ virus elimination, waste water treatment, paper and pulp bleaching, chemical oxidation, etc ${ }^{1-3}$. Due to the growing population and directly related industrial needs, it is estimated that the global $\mathrm{H}_{2} \mathrm{O}_{2}$ market demand will reach $\sim 6$ million tons by $2024^{4}$. Traditionally, the industrial production of $\mathrm{H}_{2} \mathrm{O}_{2}$ is through the energy-demanding and waste-intensive anthraquinone cycling process. This process requires large-scale production equipment, and further transportation requires handling of large amounts of unstable and hazardous solutions ${ }^{5}$. Thus, the usage of an electrochemical oxygen reduction reaction (ORR) through a 2electron pathway to produce $\mathrm{H}_{2} \mathrm{O}_{2}$ is a highly desirable method that can be safe, on-site, portable, and green ${ }^{6-21}$. However, this method critically requires the development and screening of lowcost and high-performance electrocatalysts.

Because $\mathrm{H}_{2} \mathrm{O}_{2}$ is the desired final product, the 2-electron ORR catalyst requires that the partial $\mathrm{O}_{2}$ reduction preserves the $\mathrm{O}-\mathrm{O}$ bond and possesses enhanced desorption of the ${ }^{*} \mathrm{OOH}$ intermediate at the catalyst surface, unlike the 4-electron ORR process $^{22}$. To meet these key features, the composition and electronic structure of the catalysts are critical and need to be optimized. While it has been shown that the electronic structures of $\mathrm{Pt}$ in a $\mathrm{PtHg}_{4}$ alloy and $\mathrm{Pd}$ in a Pd-Sn alloy are appropriate for 2-electron ORR process ${ }^{23,24}$, the scarcity and high-cost of the metals severely limit their scalability. Carbon-based materials doped with heteroatoms (e.g., nitrogen, oxygen, sulfur), have exhibited promising catalytic activities ${ }^{25-28}$, which can be further improved with transition metal doping to form $\mathrm{O}-\mathrm{C}(\mathrm{M}), \mathrm{N}-\mathrm{C}(\mathrm{M})$, and $\mathrm{S}-\mathrm{C}(\mathrm{M})$ structures $^{29-32}$. However, the structure-property relationship at the atomic level remains elusive, and there carry a large risk and uncertainty for these advanced catalyst designs.

In this work, we discover that the 2-electron ORR performance of carbon-based catalysts positively correlates with the Lewis acidity of the dopant. Taking the metal elements in group IIIA (Al and $\mathrm{Ga}$ ) as examples, our density functional theory (DFT) results indicate that strong Lewis acid sites (octahedral $\mathrm{M}-\mathrm{O}$ motifs) can enable the activation of neighboring carbon atoms, where the formation and desorption of the key reaction intermediate $\left({ }^{*} \mathrm{OOH}\right)$ are facilitated, and excellent catalytic activity for electrochemical $\mathrm{H}_{2} \mathrm{O}_{2}$ production is predicted. To validate the DFT calculations, we rationally fabricate $\mathrm{O}-\mathrm{C}(\mathrm{Al})$ and $\mathrm{O}-\mathrm{C}(\mathrm{Ga})$ samples with enriched atomically dispersed Lewis acids via pyrolysis of isostructural channel-type metal-organic frameworks (MOFs, MIL-53) 33-35. We find that the O-C(Al) with the stronger Lewis acidity exhibits superior activity (onset potential of $0.822 \mathrm{~V}$ vs. RHE) and selectivity (>95\%) for 2 -electron ORR. The proposed correlation is further confirmed by using Cr-doped oxidized carbon materials $(\mathrm{O}-\mathrm{C}(\mathrm{Cr})$, with moderate Lewis acidity), which expectedly exhibits moderate 2 -electron ORR performance. Using electrochemically generated $\mathrm{H}_{2} \mathrm{O}_{2}$ from an $\mathrm{O}-\mathrm{C}$ (Al) catalyst, we demonstrate an application of bleaching. This work represents a clear demonstration on establishing the relationship between the Lewis acidity with the electrocatalytic ORR activity in carbon-based catalysts.

\section{Results}

Theoretical calculations. As the aluminum compound is a commonly used strong Lewis acid ${ }^{36}$, we chose the metal elements in group IIIA ( $\mathrm{Al}, \mathrm{Ga}$, and In) as the research targets. It is qualitatively demonstrated that the Lewis acidity increases as the atomic number of elements decrease if the centers of Lewis acids are in the same main group with the same chemical environment. DFT calculations were first performed to screen possible candidates that can achieve a high electrocatalytic performance of the 2-electron $\mathrm{ORR}^{25,30}$. We constructed graphene sheet-based models with various coordination environments for simulation, as shown in Fig. 1a and Supplementary Fig. 1. However, due to the weak coordination ability of In, the simulated octahedral structures containing In were found to be thermodynamically unstable, and thus were not investigated in detail. Additional hydroxyl groups were connected to the metal center to construct saturated octahedral or tetrahedral coordination environments. We considered two types of coordination oxygen in the graphene sheet, labeled as terminal oxygen and ether oxygen, respectively. However, the geometry optimizations of key intermediates in the ORR process show that the structures containing terminal oxygen are so active that the neighboring carbon sites bind to the oxygencontaining group intensely, leading to substrate deformation and collapse. This is understandable because these phenol-like structures are quite reactive in organic chemistry. In contrast, the ether group is stable even at high temperature, and thus the a carbon atoms adjacent to the ether oxygen are supposed to be the active sites for $\mathrm{H}_{2} \mathrm{O}_{2}$ generation ${ }^{25,37}$. Accordingly, we mainly focused on two models labeled as $4 \mathrm{O}$ and $3 \mathrm{O} 1 \mathrm{C}$. For comparison purposes, the corresponding structures without metal dopants were also simulated (denoted as $4 \mathrm{O}-\mathrm{Vac}$ and $3 \mathrm{O} 1 \mathrm{C}-\mathrm{Vac}$, respectively). It is well accepted that the activity of 2-electron ORR is determined by either the step of $\mathrm{O}_{2}$ activation (Eq. (1)) or desorption of the ${ }^{*} \mathrm{OOH}$ intermediate (Eq. (2)):

$$
\begin{gathered}
*+\mathrm{O}_{2}+\mathrm{H}_{2} \mathrm{O}+e^{-} \rightarrow{ }^{*} \mathrm{OOH}+\mathrm{OH}^{-} \\
{ }^{*} \mathrm{OOH}+e^{-} \rightarrow \mathrm{HO}_{2}^{-}+{ }^{*}
\end{gathered}
$$

Herein, based on the computational hydrogen electrode (CHE) model, the commonly used descriptor, $\Delta G * \mathrm{OOH}$, was calculated to evaluate the 2-electron ORR activity of each site (Fig. $1 \mathrm{~b}$ and Supplementary Table 1$)^{25,30,32}$. Firstly, our calculations suggest that the binding strength of $\mathrm{O}_{2}$ on $a$ carbon atoms in each Vac model without metal dopants is relatively weak, in agreement with previous studies ${ }^{25,30}$. Correspondingly, the calculated $\Delta G * \mathrm{OOH}$ resides on the right leg of the volcano plot and is located far away from the summit, indicating that these carbon sites only have moderate activity (Fig. 1b). On the contrary, the carbon atoms coordinated with metal dopants (octahedral Al-O and $\mathrm{Ga}-\mathrm{O}$ ) can significantly activate the hydrogenation of $\mathrm{O}_{2}$. For an electrochemical reaction that occurs at the interface, enhancing the interaction of gas to the surface can significantly improve the reaction kinetics. On the other hand, the most favorable adsorption sites of metal-doped systems bind to ${ }^{*} \mathrm{OOH}$ so intensely that the $\mathrm{H}_{2} \mathrm{O}_{2}$ formation is hindered (as shown at the lower left of the volcano plot in Fig. 1b). Accordingly, these sites might be deeply oxidized to generate ${ }^{*} \mathrm{OH}$. Herein we further located the corresponding $* \mathrm{OH}$ intermediates and calculated free energy change of the ${ }^{*} \mathrm{OH}$ desorption step at $0.70 \mathrm{~V}$. The positive desorption energies (Supplementary Table 2) implies that $* \mathrm{OH}$ can hardly be desorbed under the experimental conditions. These sites that bind ${ }^{*} \mathrm{OOH}$ too strongly would be occupied by ${ }^{*} \mathrm{OH}$ during the oxidation process, similar to the high $* \mathrm{OH}$ coverage of oxidized metal surface in the ORR process (Supplementary Fig. 2$)^{38}$. Instead, the sites that bind ${ }^{*} \mathrm{OOH}$ relatively less strongly can achieve optimal $\Delta G *_{\mathrm{OOOH}}$ 's. The Al-doped models with stronger Lewis acidity possess better activities for 2-electron ORR than Ga-doped models. For the $4 \mathrm{O}$ and $3 \mathrm{O} 1 \mathrm{C}$ models, the overpotentials of Al-doped systems are only 0.03 and $0.22 \mathrm{~V}$, respectively. Besides, we explored the selectivity of the 2-electron process over the 4-electron process. As suggested by Guo et al. ${ }^{39}$, for the electrocatalysts favoring the generation of $\mathrm{H}_{2} \mathrm{O}_{2}$ rather than $\mathrm{H}_{2} \mathrm{O}$, the potential barrier for $\mathrm{H}_{2} \mathrm{O}_{2}$ desorption should be 


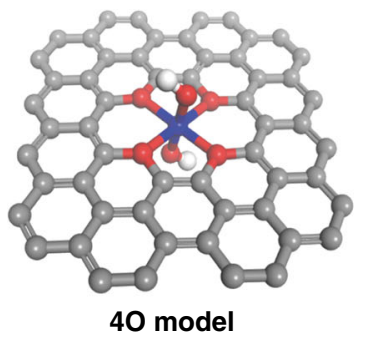

b

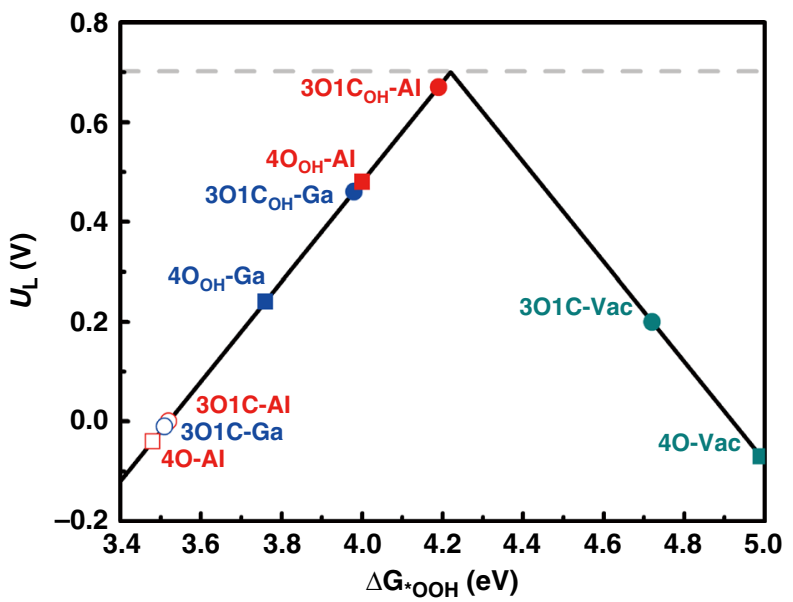

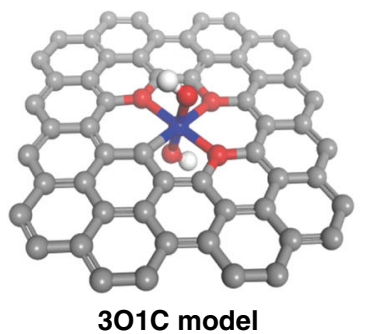

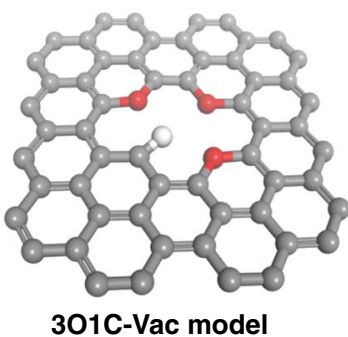

C

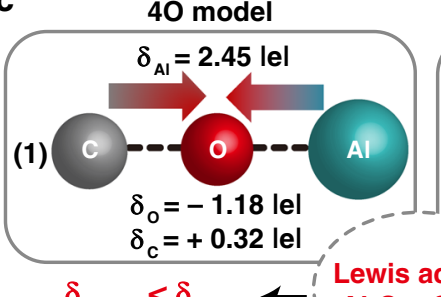

40 model

$301 \mathrm{C}$ model
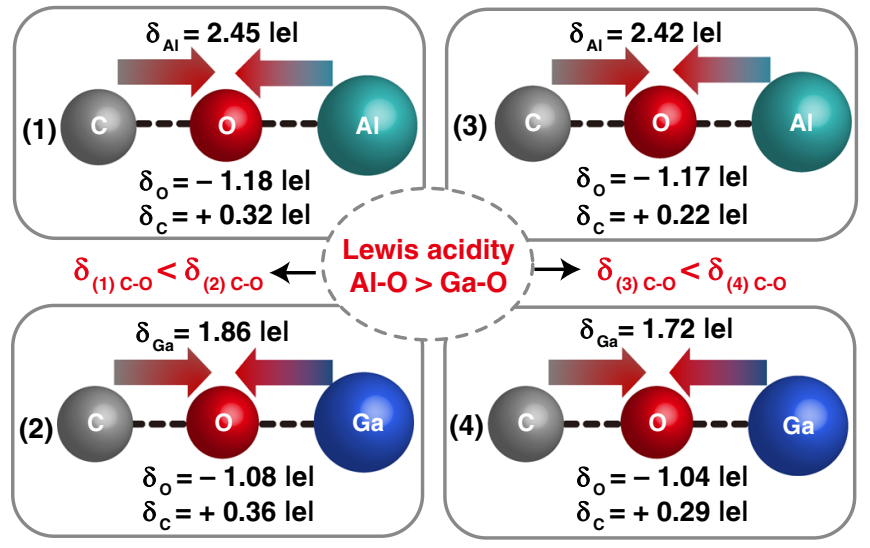

Lewis acid: enhance the electron density of adjacent $C$

Fig. 1 The atomically dispersed Lewis acid in an oxygen-rich carbon catalyst enhanced the catalytic performance of the 2-electron ORR reaction. a Four DFT calculation models with potential active sites for electrochemical production of $\mathrm{H}_{2} \mathrm{O}_{2}$. Blue, red, white, and gray balls denote metal, $\mathrm{O}, \mathrm{H}$, and $\mathrm{C}$ atoms, respectively. $\mathbf{b}$ The simulated activity volcano plot for 2-electron ORR path to $\mathrm{H}_{2} \mathrm{O}_{2}$. The theoretical equilibrium potential is shown as a gray dashed line. c Illustration showing the effect of Lewis acidity to the electron distribution of adjacent carbon atom.

lower than that for the hydrogenation of $\mathrm{OOH}^{*}$ to $\mathrm{O}^{*}$. The barriers are listed in Supplementary Table 3, where one can see that the 2-electron process is thermodynamically favorable or comparable to the 4 -electron process. Considering the fact that the 2-electron process is also kinetically preferred, we believe that the 2-electron process should be dominant.

Furthermore, Bader charge analysis was employed to elucidate the effect of the metal centers (Fig. 1c). The well-established theory on Lewis acid catalysis demonstrates that metal atoms can coordinate with an electronegative atom with the lone-pair, resulting in charge transfer and a more electronegative lone-pair donor $^{40}$. In the $4 \mathrm{O}-\mathrm{Vac}$ model, the ether oxygen and the potentially active carbon possess atomic charges of -0.98 and $+0.65|e|$, respectively, which means that electrons accumulated on the $\mathrm{C}-\mathrm{O}$ bonds were $-0.33|e|$. In comparison, Lewis acid coordination allows for electron transfer from the metal to the $\mathrm{C}-\mathrm{O}$ bond, resulting in a more negative charge on the oxygen and a less positive charge on the a carbon. In the 40 model, the charges on oxygen and $\alpha$ carbon are -1.18 and $+0.32|e|$ in the Al-containing system, while in a Ga-containing system, they are -1.08 and $+0.36|e|$, respectively. Therefore, more electrons can be accumulated on the $\mathrm{C}-\mathrm{O}$ bonds $(-0.86$ and $-0.72|e|$ for $\mathrm{Al}-$ containing and Ga-containing systems, respectively) once Lewis acid sites are introduced. The higher electron accumulation or density on the $\mathrm{C}-\mathrm{O}$ bond (i.e., carbon site with a less positive charge) can enhance the interaction between $\mathrm{O}_{2}$ molecules and $\alpha$ carbon, and thus facilitate the formation of $* \mathrm{OOH}$ intermediates. Similarly, in the 3O1C model, the carbon atom directly binds to the metal center and withdraws electrons, resulting in higher electron density for the carbon atom. Since the Lewis acidity of $\mathrm{Al}$-center is stronger than that of $\mathrm{Ga}$-center, $3 \mathrm{O} 1 \mathrm{C}-\mathrm{Al}$ yields an even more negative atomic charge $[-0.95$ and $-0.75|e|$ for $\mathrm{O}-\mathrm{C}$
(Al) and $\mathrm{O}-\mathrm{C}(\mathrm{Ga})$, respectively] and higher activity for ${ }^{*} \mathrm{OOH}$ formation. Moreover, we further depict the deformation charge density to illustrate the charge transfer between the oxygen-doped carbon layer and metal motif (Supplementary Fig. 3). It is clearly seen that the electrons tend to accumulate on the a carbon after coordinating to $\mathrm{Al}$ or $\mathrm{Ga}$, also consistent with the atomic charge analysis. From the perspective of electronic structure, the effect of functional motif has already been demonstrated both experimentally and theoretically. It was reported that the nitrogen dopant in carbon materials withdraws electron from the adjacent $\mathrm{C}$ atom, leading to a reduced work function, increased density of $\pi$ states close to Fermi level ${ }^{41}$. As a result, the 4 -electron ORR process is promoted. In contrast, the high work function of oxygen-doped porous carbon is related to the dominant 2-electron process ${ }^{12}$. Introducing Lewis acid that coordinates to oxygen may further result in electron accumulation on active site and consequently promote the 2-electron process. These properties, including acidity/basicity, work function, and density of states near the Fermi level, are all correlated with charge density. Moreover, due to electrostatic interaction, the binding strength between negatively or less positively charged carbon and generated electronegative ${ }^{*} \mathrm{OOH}$ can be weakened, thereby enhancing the desorption of $* \mathrm{OOH}$. As a result, the carbon atom binding to $\mathrm{Al}$ may exhibit the highest performance of the 2-electron ORR reaction. Indeed, as shown in the activity volcano plot (Fig. 1b), the potential active sites in the $\mathrm{Al}$-doped system are located closer to the volcano summit than those in the Ga-doped system.

Synthesis and characterizations of $\mathrm{O}-\mathrm{C}(\mathrm{M})$ catalysts. Two isomorphic MOFs, MIL-53(Al, Ga), with enriched octahedral M-O clusters were chosen as the representative precursors. Powder 
a

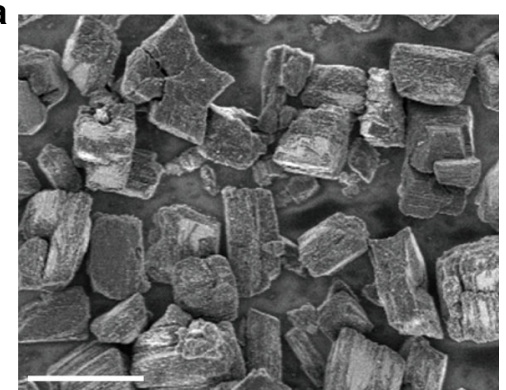

d
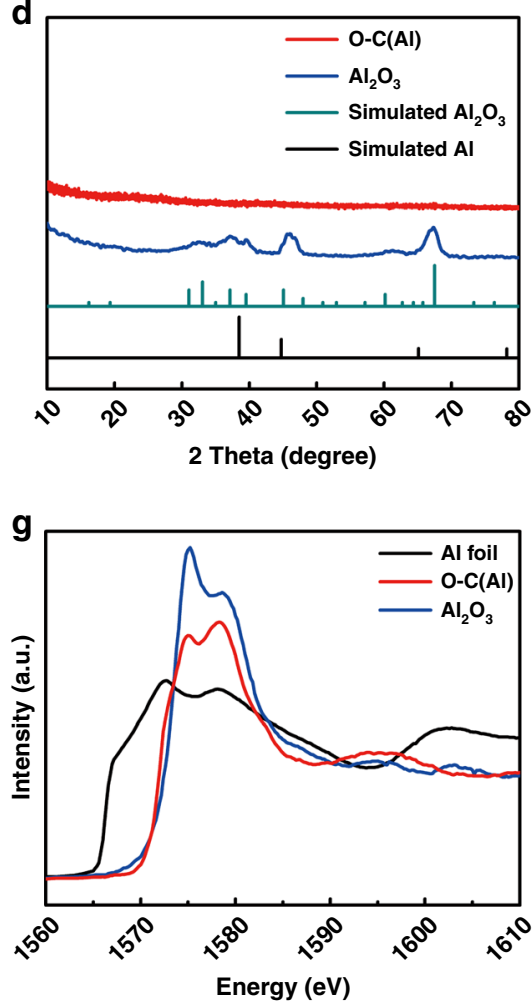

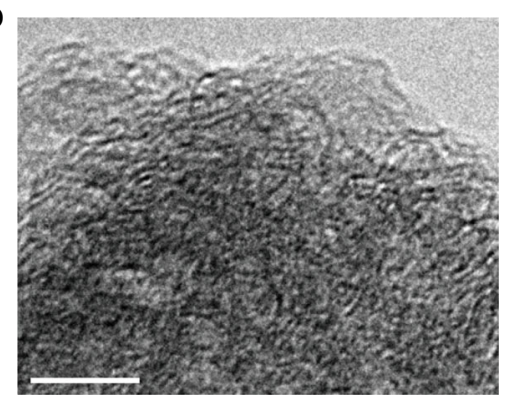

e

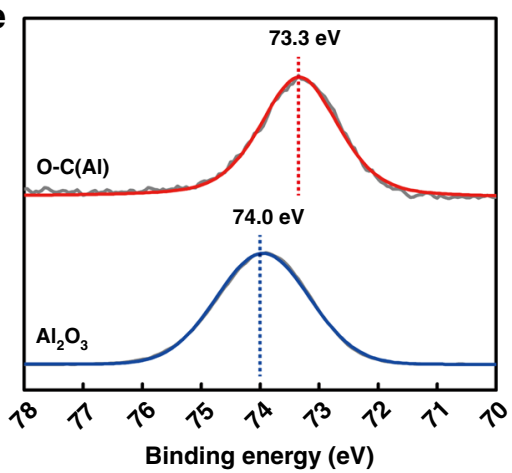

h

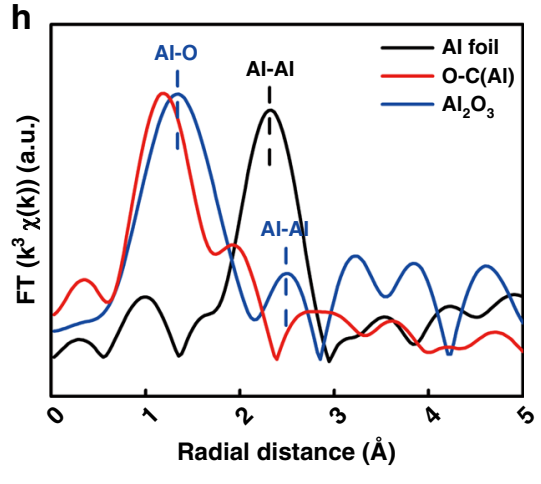

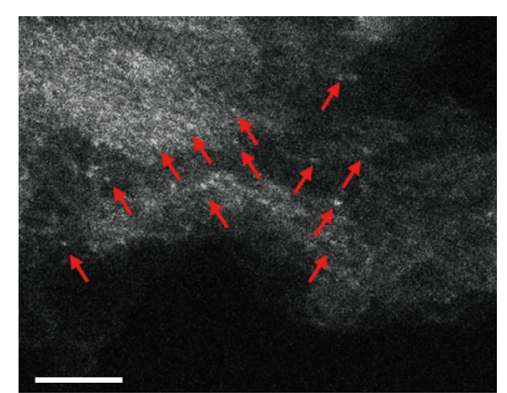

f

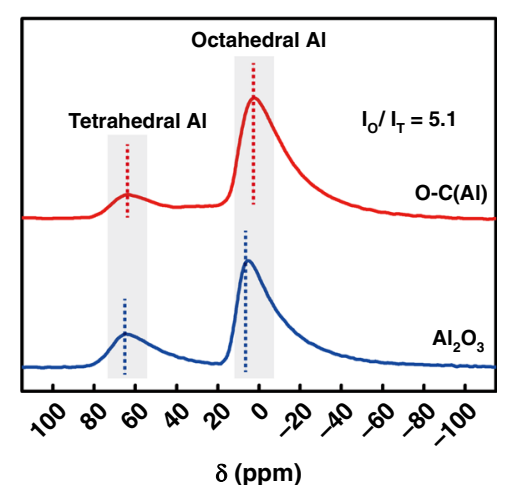

i

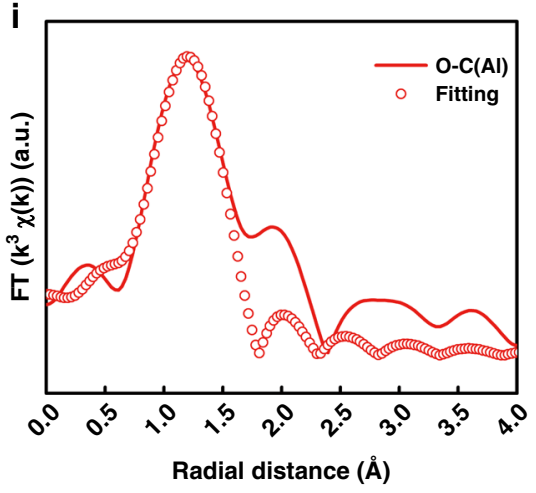

Fig. 2 Synthesis and structural characterization of $\mathbf{O}-\mathbf{C ( M )}$. a SEM image of O-C(AI), scale bar is $5 \mu$ m. High-resolution TEM (b) and aberrationcorrected HAADF-STEM (c) images of O-C(Al), scale bars are 5 and $2 \mathrm{~nm}$, respectively. $\mathbf{d}$ Powder XRD patterns for simulated $\mathrm{Al}$ and $\mathrm{Al}_{2} \mathrm{O}_{3}$, assynthesized $\mathrm{O}-\mathrm{C}(\mathrm{Al})$ and commercial $\mathrm{Al}_{2} \mathrm{O}_{3}$. e High-resolution XPS spectra of $\mathrm{Al} 2 \mathrm{p}$ in O-C(AI) and $\mathrm{Al}_{2} \mathrm{O}_{3}$. f $\mathrm{Al}$ solid-state NMR patterns of O-C(AI) and $\mathrm{Al}_{2} \mathrm{O}_{3}$. $\mathbf{g}$ Al K-edge XANES and $\mathbf{h} \mathrm{k}^{3}$-weighted Fourier transform of EXAFS spectra. $\mathbf{i}$ The EXAFS R-space fitting curve of $\mathrm{O}-\mathrm{C}(\mathrm{Al})$.

X-ray diffraction (XRD) patterns and scanning electron microscopy (SEM) images show the successful synthesis of isomorphic MIL-53(Al, Ga) with highly crystalline and regular morphology (Supplementary Figs. 4 and 5). Upon a pyrolysis $\left(800^{\circ} \mathrm{C}\right.$ for $2 \mathrm{~h}$ in $\mathrm{N}_{2}$ atmosphere) and room temperature chemical etching process (immersed in $0.1 \mathrm{M} \mathrm{NaOH}$ for $12 \mathrm{~h}$ ), the $\mathrm{O}-\mathrm{C}(\mathrm{M})$ catalysts with atomically dispersed Lewis acids sites ( $\mathrm{Al}-\mathrm{O}$ and $\mathrm{Ga}-\mathrm{O}$ species) were prepared with highly maintained original morphologies (Fig. 2a and Supplementary Fig. 6).

Further characterization was necessary to elucidate how the structure of the catalysts impacts or determines the catalytic performance. From the DFT studies, we first studied $\mathrm{O}-\mathrm{C}(\mathrm{Al})$, as it was predicted to be the best catalyst for 2-electron ORR. Elemental mapping at the microstructural level via SEM indicated that $\mathrm{Al}$ and $\mathrm{O}$ were uniformly distributed in the carbon matrix (Supplementary Fig. 7) for O-C(Al), indicating that the MOF precursor has an equidistribution effect. High-resolution transmission electron microscopy (TEM) images (Fig. 2b) also proved that there were no identifiable $\mathrm{Al}$ or $\mathrm{Al}_{2} \mathrm{O}_{3}$ nanoparticles in $\mathrm{O}-\mathrm{C}$ (Al) sample, while aberration-corrected high angle annular dark- field scanning TEM (HAADF-STEM) observations demonstrated that the $\mathrm{Al}$ species were atomically dispersed within the carbon matrix (Fig. 2c), consistent with XRD analysis (Fig. 2d). Inductively coupled plasma (ICP) results also showed that the content of the $\mathrm{Al}$ species was as high as $5.85 \mathrm{wt} \%$ in $\mathrm{O}-\mathrm{C}$ (Al). Similarly, the characterizations showed that there were many atomically dispersed $\mathrm{Ga}$ species (Supplementary Fig. 8) in $\mathrm{O}-\mathrm{C}(\mathrm{Ga})$. However, there is a small amount of $\mathrm{Ga}_{2} \mathrm{O}_{3}$ that remains even after chemical etching (Supplementary Fig. 9), which may arise from the protection of carbon layers on the surface of $\mathrm{Ga}_{2} \mathrm{O}_{3}$.

More critically, we used X-ray photoelectron spectroscopy (XPS) measurements to determine the binding energy and chemical signatures of the $\mathrm{Al}$ species in the $\mathrm{O}-\mathrm{C}(\mathrm{Al})$ sample. XPS revealed the presence of $\mathrm{Al}, \mathrm{O}$, and $\mathrm{C}$ (Supplementary Fig. 10) expectedly, with a high-resolution single-peaked $\mathrm{Al} 2 p$ spectrum at a binding energy of $73.3 \mathrm{eV}$ (Fig. 2e). It should be noted that this peak position was located between that of $\mathrm{Al}_{2} \mathrm{O}_{3}$ $(74.0 \mathrm{eV})$ and $\mathrm{Al}(72.7 \mathrm{eV})^{42,43}$, illustrating that the valence state of the $\mathrm{Al}$ species in $\mathrm{O}-\mathrm{C}(\mathrm{Al})$ was between $\mathrm{Al}^{0}$ and $\mathrm{Al}^{3+}$. 
Compared with $\mathrm{O}-\mathrm{C}$ sample, the high-resolution XPS spectra of $\mathrm{C} 1 s$ and $\mathrm{O} 1 s$ in the $\mathrm{O}-\mathrm{C}(\mathrm{Al})$ catalyst demonstrated that the binding energy of $\mathrm{O}$ and $\mathrm{C}$ atoms adjacent to $\mathrm{Al}$ atom were both shifted to lower binding energy (Supplementary Fig. 11), which clearly indicated that more electrons were accumulated on the $\mathrm{O}$ and $\mathrm{C}$ atoms adjacent to $\mathrm{Al}$ atom, consistent with the computational analysis of deformation charge density (Supplementary Fig. 3) and Bader charge (Fig. 1c). Nuclear magnetic resonance (NMR) was used as an additional method to determine the coordination of the $\mathrm{Al}$ species, as it is sensitive to the coordination environment. The solid-state NMR of $\mathrm{Al}$ yielded two peaks centered at 3 and $63 \mathrm{ppm}$, which can be assigned to octahedral and tetrahedral Al-O species, respectively (Fig. 2f) ${ }^{44}$. The high-intensity ratio $\left(I_{\mathrm{O}} / I_{\mathrm{T}}=5.1\right)$ of the octahedral band and tetrahedral band also indicated that the octahedral $\mathrm{Al}-\mathrm{O}$ species was predominant. In order to confirm the structure of $\mathrm{O}-\mathrm{C}(\mathrm{Al})$ at the atomistic level, X-ray absorption spectroscopy (XAS), a powerful technique to determine the coordination environment and valence state of the target atoms was employed. The X-ray absorption near-edge structure (XANES) spectra of $\mathrm{O}-\mathrm{C}(\mathrm{Al})$ in Fig. $2 \mathrm{~g}$ illustrated that the valence state of $\mathrm{Al}$ species in $\mathrm{O}-\mathrm{C}(\mathrm{Al})$ was situated between that of $\mathrm{Al}^{0}$ and $\mathrm{Al}^{3+}$, consistent with the afore-mentioned XPS result. Moreover, the result can be further verified by the differential curves obtained from the XANES data (Supplementary Fig. 12). The extended X-ray absorption fine structure (EXAFS) spectra for $\mathrm{O}-\mathrm{C}(\mathrm{Al})$ exhibited the main peak at $\sim 1.2 \AA$, which could be attributed to $\mathrm{Al}-\mathrm{O}(\mathrm{C})$ scattering paths. Importantly, the fingerprinting signal peaks of $\mathrm{Al}-\mathrm{Al}$ interactions in $\mathrm{Al}$ foil $(\sim 2.3 \AA)$ and $\mathrm{Al}_{2} \mathrm{O}_{3}(\sim 2.5 \AA)$ cannot be observed in the curve of $\mathrm{O}-\mathrm{C}(\mathrm{Al})^{45}$. Therefore, it can be concluded that $\mathrm{Al}$ atoms were atomically dispersed in $\mathrm{O}-\mathrm{C}(\mathrm{Al})$. Furthermore, the best fitting result of the obtained EXAFS data reveals that the coordination number of Al was about 6 (Fig. 2i and Supplementary Table 4), which is in agreement with the result of solid-state NMR of $\mathrm{O}-\mathrm{C}(\mathrm{Al})$ and the constructed model structure in DFT calculations. Unfortunately, the XAS data cannot directly prove the existence of $\mathrm{Al}-\mathrm{C}$ as the bond length of $\mathrm{Al}-\mathrm{C}$ and $\mathrm{Al}-\mathrm{O}$ are very close. Thus, all characterizations suggest that the pyrolysis of the MOF, MIL-53(Al), were successful in the fabrication of carbon-based catalyst featuring atomically dispersing the metal species in an octahedral environment with valences that are predicted to regulate the electron distribution of a carbon atom and in turn positively affect the 2-electron ORR.

Electrocatalytic 2-electron ORR characterizations. To determine the performance of the $\mathrm{O}-\mathrm{C}(\mathrm{M})$ catalysts, the ORR activity and selectivity of all electrocatalysts were evaluated on a rotating ringdisk electrode with a collection efficiency of 0.35 (calibrated by the redox reaction of $\left[\mathrm{Fe}\left(\mathrm{CN}_{6}\right)\right]^{4-} /\left[\mathrm{Fe}\left(\mathrm{CN}_{6}\right)\right]^{3-}$, Supplementary Fig. 13) in $0.1 \mathrm{M} \mathrm{NaOH}$ (Fig. 3a, b). The disk electrode and Pt ring electrode were responsible for the $\mathrm{O}_{2}$ reduction current (solid line) and $\mathrm{H}_{2} \mathrm{O}_{2}$ oxidation current (dashed line), respectively. The ORR can undergo either a 2-electron or 4-electron pathway, while the former pathway is preferred for all $\mathrm{O}-\mathrm{C}(\mathrm{M})$ catalysts. An ultrahigh onset potential $\left(0.822 \mathrm{~V}\right.$ at $0.1 \mathrm{~mA} \mathrm{~cm}^{-2} \mathrm{H}_{2} \mathrm{O}_{2}$ current $)$ and selectivity $(>95 \%)$ within the potential range of $0.45-0.65 \mathrm{~V}$ vs. RHE were observed for the $\mathrm{O}-\mathrm{C}(\mathrm{Al})$ catalyst, as shown in Fig. 3a, $\mathrm{b}$. It should be noted that this onset potential is superior to those of so-far reported $\mathrm{H}_{2} \mathrm{O}_{2}$ catalysts (Supplementary Table 5). Moreover, the Tafel Slope of $\mathrm{O}-\mathrm{C}(\mathrm{Al})$ sample $\left(\sim 52 \mathrm{mV} \mathrm{dec}^{-1}\right)$ is lower than other $\mathrm{O}-\mathrm{C}(\mathrm{M})$ samples, indicating its faster reaction kinetics. We have also tuned the pyrolysis temperature $\left(700-900^{\circ} \mathrm{C}\right)$ to synthesize $\mathrm{O}-\mathrm{C}(\mathrm{Al})$ catalysts and found that temperature did not affect the high catalytic performance of the 2-electron ORR using the $\mathrm{O}-\mathrm{C}(\mathrm{Al})$ catalyst, demonstrating its robustness and reproducibility (Supplementary Figs. 14 and 15). Compared with the $\mathrm{O}-\mathrm{C}(\mathrm{Al})$ catalyst, the $\mathrm{O}-\mathrm{C}(\mathrm{Ga})$ catalyst exhibited slightly decreased onset potential, selectivity, and Tafel slope (Fig. 3a-c). The proposed correlation not only is applicable for main group metals but also can be further extended to transition metals. An $\mathrm{O}-\mathrm{C}(\mathrm{Cr})$ catalyst (detailed characterizations can be found in Supplementary Fig. 16) with moderate Lewis acidity possessed moderate ORR performance (Supplementary Fig. 17), demonstrating the effectiveness of constructing atomically dispersed $\mathrm{M}-\mathrm{O}$ Lewis acid sites on electrochemical oxygen reduction to $\mathrm{H}_{2} \mathrm{O}_{2}$ production. While transition metal-doped carbon materials have already been identified as highly active catalysts for 2-electron ORR, the previously reported transition metal sites (e.g., $\mathrm{Co}, \mathrm{Fe}$ ) in the catalysts may serve as the active sites for 4-electron $\mathrm{ORR}^{46,47}$ and the high selectivity cannot be maintained under high overpotentials (Fig. 3d and Supplementary Table 6) ${ }^{30,48}$. On the contrary, main group metals, such as $\mathrm{Al}$ and $\mathrm{Ga}$ in this work, are thought to be catalytically inactive due to the tight binding of the metal center with the hydroxyl group intermediate that leads to the suppression of the intermediate product desorption. The oxygenrich carbon catalyst (preparation in methods) without $\mathrm{M}-\mathrm{O}$ clusters exhibited poor catalytic performance (onset potential of 0.698 $\mathrm{V}$ and selectivity of $\sim 85 \%$ ), unequivocally indicating the significant role of Lewis acid sites in enhancing the reduction of $\mathrm{O}_{2}$ to $\mathrm{H}_{2} \mathrm{O}_{2}$. More importantly, the activity and selectivity can be well maintained during long-term testing $(\sim 10 \mathrm{~h})$, indicating the excellent recyclability and the stability of $\mathrm{O}-\mathrm{C}(\mathrm{Al})$ (Fig. 3e).

As $\mathrm{M}_{2} \mathrm{O}_{3}(\mathrm{M}=\mathrm{Cr}, \mathrm{Ga})$ and atomically dispersed $\mathrm{M}-\mathrm{O}$ sites coexisted in the $\mathrm{O}-\mathrm{C}(\mathrm{M})$ catalysts, we measured the ORR performance of pure $\mathrm{M}_{2} \mathrm{O}_{3}$ to exclude their possible contribution. The selectivity of $\mathrm{Cr}_{2} \mathrm{O}_{3}$ and $\mathrm{Ga}_{2} \mathrm{O}_{3}$ was found to be only $\sim 58 \%$ and $\sim 61 \%$ (Supplementary Fig. 18), respectively, revealing their inert nature and negligible contribution for the 2-electron ORR. This is further proof that the high ORR activity and selectivity of $\mathrm{O}-\mathrm{C}(\mathrm{Cr})$ and $\mathrm{O}-\mathrm{C}(\mathrm{Ga})$ catalysts can be attributed to the atomically dispersed $\mathrm{Cr} / \mathrm{Ga}$ species rather than the $\mathrm{M}_{2} \mathrm{O}_{3}$ nanoparticles covered in the carbon matrix.

Encouraged by the improved activity of $\mathrm{O}-\mathrm{C}(\mathrm{M})$, group IIIA metal elements ( $\mathrm{Al}$ and $\mathrm{Ga}$ ) doping has been attempted to enhance the performance of other carbon-based catalysts, such as nitrogen-rich and sulfur-rich carbon (denoted as $\mathrm{N}-\mathrm{C}(\mathrm{M})$ and $\mathrm{S}-\mathrm{C}(\mathrm{M})$, respectively). As expected, in both $\mathrm{N}-\mathrm{C}(\mathrm{M})$ and $\mathrm{S}-\mathrm{C}(\mathrm{M})$ system, the $\mathrm{H}_{2} \mathrm{O}_{2}$ selectivity of $\mathrm{M}$-doped $(\mathrm{M}=\mathrm{Al}, \mathrm{Ga})$ carbon was higher than that of no metal-doped carbon, and Al-doped catalyst with stronger Lewis acidity exhibited superior $\mathrm{H}_{2} \mathrm{O}_{2}$ selectivity (Supplementary Figs. 19 and 20), which was in good agreement with the results of DFT calculations (Supplementary Fig. 21 and Supplementary Table 7). All results unambiguously demonstrate that group IIIA metal ( $\mathrm{Al}$ and $\mathrm{Ga}$ ) doping is an effective and universal strategy to improve the 2-electron ORR performance of carbon-based catalysts and the $\mathrm{H}_{2} \mathrm{O}_{2}$ selectivity of catalysts is positively correlated with the Lewis acidity of the dopant.

Another method we used to prove that the Lewis acidity is crucial in the 2-electron ORR activity was through pyridine poisoning. As pyridine's lone-pair has the ability to strongly coordinate with unoccupied orbitals of transition metals, it can fully poison the catalytic activity of the Lewis acid sites ${ }^{49}$. Once the atomically dispersed Lewis acid sites (octahedral $\mathrm{Al}-\mathrm{O}$ ) in $\mathrm{O}-\mathrm{C}(\mathrm{Al})$ were effectively poisoned by pyridine (denoted as $\mathrm{O}-\mathrm{C}$ (Al)-P), the catalytic $\mathrm{H}_{2} \mathrm{O}_{2}$ selectivity was sharply reduced to $\sim 80 \%$ (Fig. $3 \mathrm{c}$ ), close to that of the Vac, O-C sample. The Lewis acidity of all electrocatalysts was measured via the temperatureprogrammed desorption of ammonia ( $\left.\mathrm{NH}_{3}-\mathrm{TPD}\right)$, which is reliant on the binding strength between the adsorbed $\mathrm{NH}_{3}$ and the adsorption sites (Fig. 3f) ${ }^{50-52}$. Generally, the adsorption site with stronger acidity presents a stronger binding strength with 

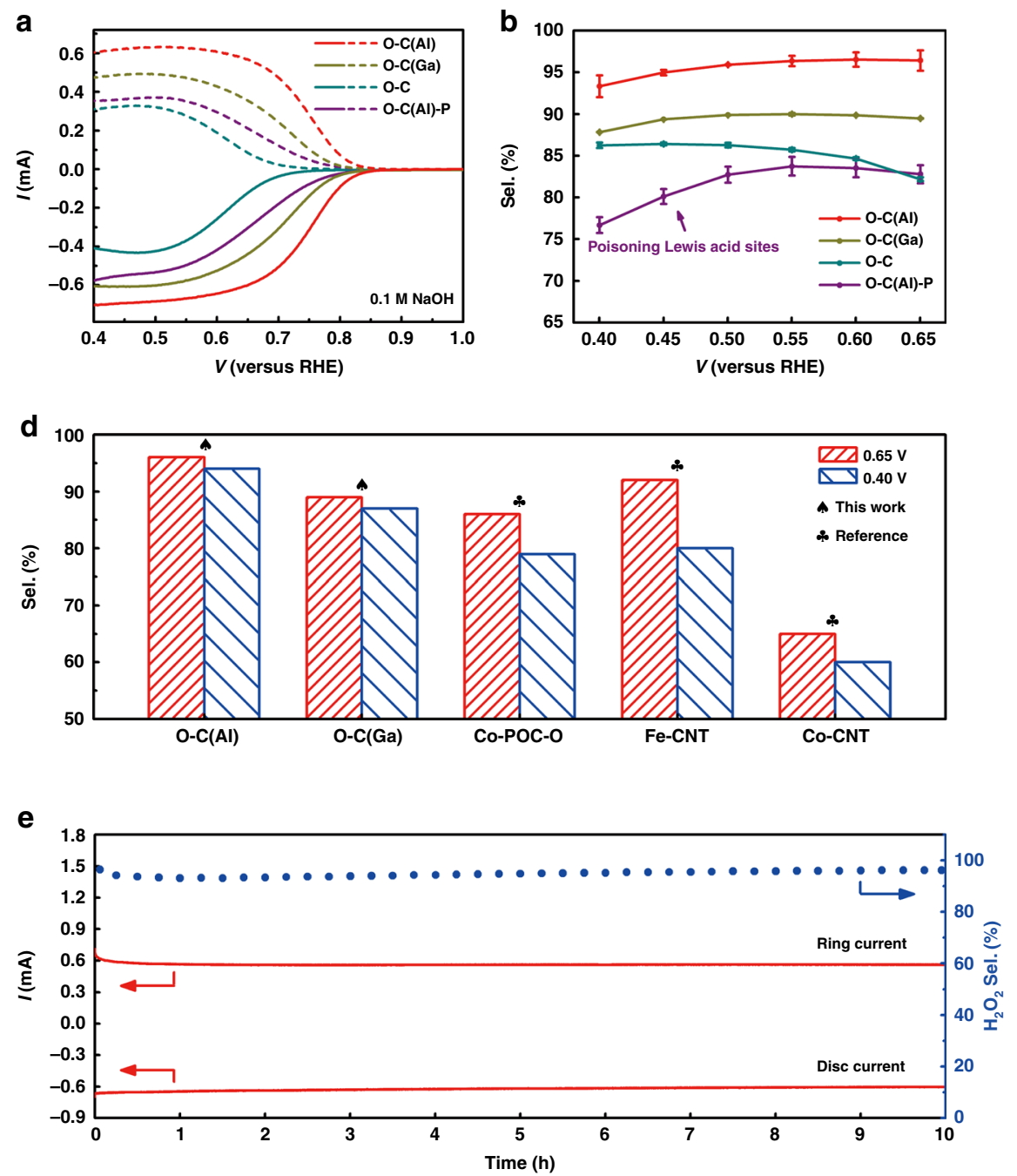

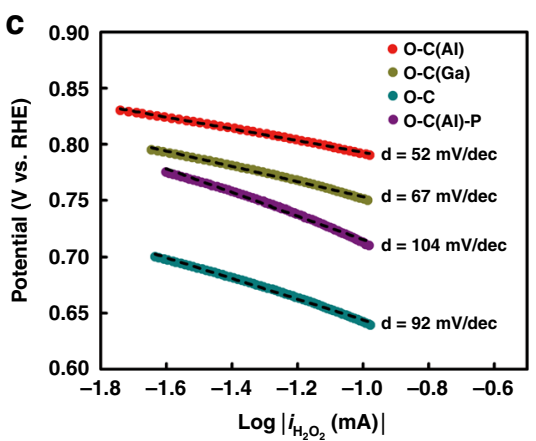

$\mathbf{f}$
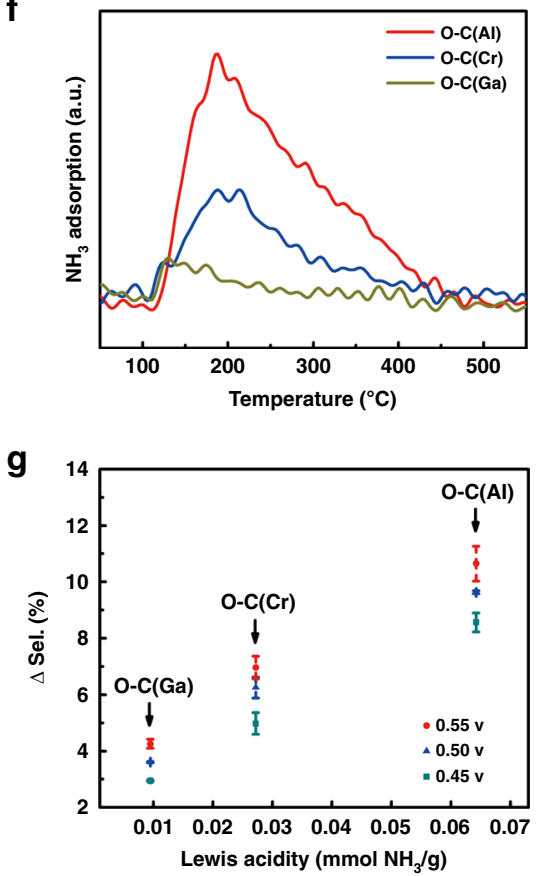

Fig. 3 Electrocatalytic performance of $\mathbf{O}-\mathbf{C}(\mathbf{M})$ and $\mathbf{O}-\mathbf{C}$ towards 2-electron $\mathbf{O R R}$ in $\mathbf{0 . 1} \mathbf{M} \mathbf{~ N a O H}$. a Illustration showing the process of $\mathrm{O}_{2}$ reduction to $\mathrm{H}_{2} \mathrm{O}_{2}$ over $\mathrm{O}-\mathrm{C}(\mathrm{M})$ catalysts. Linear sweep voltammetry (LSV) curves of O-C(AI), O-C(Ga), O-C, and O-C(AI)-P (solid lines) together with the corresponding $\mathrm{H}_{2} \mathrm{O}_{2}$ currents on the ring electrode (dashed lines) recorded at $1600 \mathrm{rpm}$. b Calculated $\mathrm{H}_{2} \mathrm{O}_{2}$ selectivity during the potential sweep. c Tafel slopes of $\mathrm{O}-\mathrm{C}(\mathrm{Al}), \mathrm{O}-\mathrm{C}(\mathrm{Ga}), \mathrm{O}-\mathrm{C}$, and $\mathrm{O}-\mathrm{C}(\mathrm{Al})-\mathrm{P}$ in $0.1 \mathrm{M} \mathrm{NaOH}$ solution. d The $\mathrm{H}_{2} \mathrm{O}_{2}$ selectivity of $\mathrm{O}-\mathrm{C}(\mathrm{M})$ and reference catalysts at low overpotential $(0.65 \mathrm{~V})$ and high overpotential $(0.4 \mathrm{~V})$. e Stability measurement of $\mathrm{O}-\mathrm{C}(\mathrm{Al})$ at a fixed disk potential of $\sim 0.47 \mathrm{~V} . \mathbf{f} \mathrm{NH}_{3}-\mathrm{TPD}$ profiles of O-C(Al), O-C(Cr), and $\mathrm{O}-\mathrm{C}(\mathrm{Ga}) . \mathbf{g}$ The correlation between the increased selectivity (compared with $\mathrm{O}-\mathrm{C}$ catalyst) and Lewis acidity of $\mathrm{O}-\mathrm{C}(\mathrm{M})$ catalysts at various potentials.

$\mathrm{NH}_{3}$ and requires higher temperatures for $\mathrm{NH}_{3}$ desorption. The results demonstrated that $\mathrm{O}-\mathrm{C}(\mathrm{Al})$ exhibited the strongest Lewis acidity (i.e., $\mathrm{Al}$ in $\mathrm{O}-\mathrm{C}(\mathrm{Al})$ in a state of less electrons) while $\mathrm{O}-\mathrm{C}(\mathrm{Ga})$ exhibited the weakest Lewis acidity (Supplementary Fig. 22). More valence electrons (outermost electrons) of aluminum in $\mathrm{O}-\mathrm{C}(\mathrm{Al})$ were delocalized to the surrounding oxygen-rich carbon $(\mathrm{O}-\mathrm{C})$ substrate, which is consistent with the Bader charges analysis (Fig. 1c). The selectivity of reducing $\mathrm{O}_{2}$ to $\mathrm{H}_{2} \mathrm{O}_{2}$ over $\mathrm{O}-\mathrm{C}(\mathrm{M})$ is closely related to its acidity, where Fig. $3 \mathrm{~g}$ demonstrates a nearly linear correlation between the increased selectivity ( $\Delta$ sel., compared with $\mathrm{O}-\mathrm{C}$ catalyst) and Lewis acidity, which is in good agreement with the conclusions from DFT calculations. Compared with the $\mathrm{O}-\mathrm{C}$ system, integration of the Lewis acid sites (M-O) into the oxygen-rich carbon to form $\mathrm{O}-\mathrm{C}$ (M) can effectively improve the formation of the key intermediate $\left({ }^{*} \mathrm{OOH}\right)$, which is critical for the 2 -electron ORR reaction (Fig. 1b). However, the excessively strong adsorption strength will affect the desorption of $* \mathrm{OOH}$ and decrease the selectivity of the reaction. The $\mathrm{O}-\mathrm{C}(\mathrm{M})$ with the stronger Lewis acidity means that more valence electrons from the metal centers are donated to the neighboring carbon atoms, increasing the electron density of the carbon atoms (Fig. 1c). The rich-electron structure is conducive to partially reduce the over-binding strength to make the $\Delta G *^{*} \mathrm{OOH}$ closer to the theoretical equilibrium potential. As a result, the catalytic performance of the catalyst towards 2-electron ORR reaction is gradually improved along with the increasing of the Lewis acidity of the catalyst and is arranged in the followed order of $\mathrm{O}-\mathrm{C}(\mathrm{Ga})<\mathrm{O}-\mathrm{C}(\mathrm{Cr})<\mathrm{O}-\mathrm{C}(\mathrm{Al})$.

This enhancement of catalytic performance over oxygen-rich carbon with atomically dispersed Lewis acid sites was also observed in a neutral electrolyte $(0.1 \mathrm{M}$ phosphate-buffered saline, PBS, $\mathrm{pH} \sim 7$ ). Compared with $\mathrm{O}-\mathrm{C}$ (selectivity: $\sim 75 \%$; onset potential: $0.266 \mathrm{~V}$ vs. $\mathrm{RHE}$ at $0.1 \mathrm{~mA} \mathrm{~cm}^{-2} \mathrm{H}_{2} \mathrm{O}_{2}$ current), $\mathrm{H}_{2} \mathrm{O}_{2}$ generation was significantly improved with the $\mathrm{O}-\mathrm{C}(\mathrm{Al})$ catalyst, among which the onset potential shifted in a positive direction by $\sim 260 \mathrm{mV}(0.526 \mathrm{~V}$ vs. RHE) and the selectivity increased to $\sim 90 \%$ (Fig. $4 \mathrm{a}, \mathrm{b}$ ). The stability of the $\mathrm{O}-\mathrm{C}(\mathrm{Al})$ was also examined under long-term testing $(\sim 10 \mathrm{~h})$, in which the remarkable changes in activity and selectivity cannot be measured (Fig. 4c). The gradual decay of the ring current in PBS was caused 

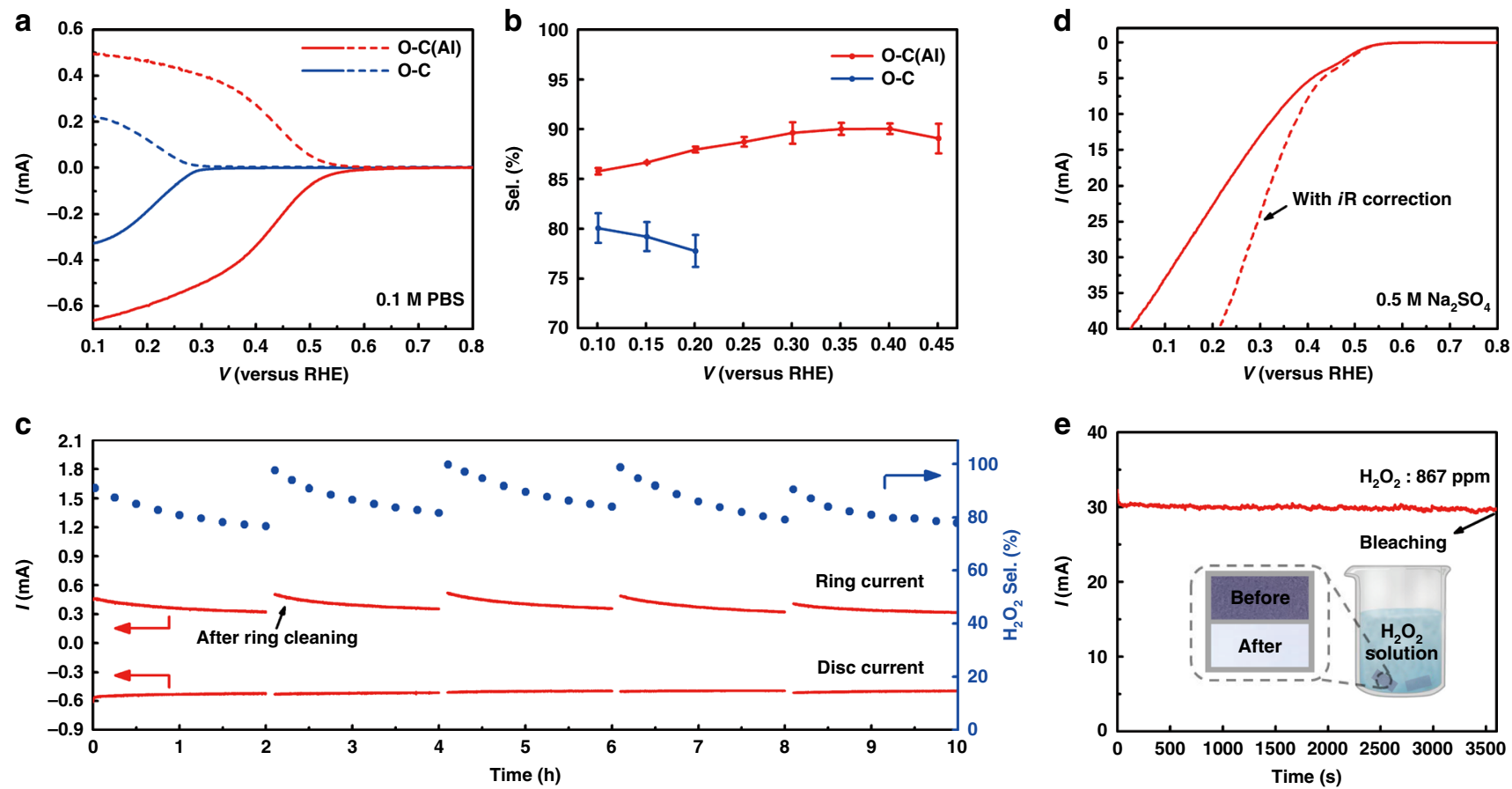

Fig. 4 ORR performance of $\mathbf{O}-\mathbf{C}(\mathbf{A I})$ and $\mathbf{O}-\mathbf{C}$ in neutral neutral electrolyte. a $L S V$ curves of $\mathrm{O}-\mathrm{C}(\mathrm{AI})$ and $\mathrm{O}-\mathrm{C}$ (solid lines) together with the corresponding $\mathrm{H}_{2} \mathrm{O}_{2}$ currents on the ring electrode (dashed lines) recorded at $1600 \mathrm{rpm}$ in $0.1 \mathrm{M} \mathrm{PBS}$. b Calculated $\mathrm{H}_{2} \mathrm{O}_{2}$ selectivity at different potentials. c Stability measurement of $\mathrm{O}-\mathrm{C}(\mathrm{Al})$ at a fixed disk potential of $\sim 0.2 \mathrm{~V}$. The ring electrode was refreshed by rapid scan at negative potentials every two hours. $\mathbf{d} \mathrm{LSV}$ of $\mathrm{O}-\mathrm{C}(\mathrm{Al})$ catalyst in $0.5 \mathrm{M} \mathrm{Na}_{2} \mathrm{SO}_{4}$ via a $\mathrm{H}$-cell electrolyzer. e Bulk electrolysis at a constant current density of $30 \mathrm{~mA} \mathrm{~cm}^{-2}$ in $0.5 \mathrm{M}$ $\mathrm{Na}_{2} \mathrm{SO}_{4}$. Insert: the bleaching demonstration of blue litmus paper with the generated $\mathrm{H}_{2} \mathrm{O}_{2}(\sim 867 \mathrm{ppm})$.

by the anion poisoning rather than the degradation of current, which can be restored after cleaning.

In addition, practical electrolysis was demonstrated in an $\mathrm{H}$-cell, where the $\mathrm{O}-\mathrm{C}(\mathrm{Al})$ catalyst was casted onto a carbon paper with the loading amount of $1 \mathrm{mg} \mathrm{cm}^{-2}$. The result shows that the current density of the catalyst is significantly improved compared with that in the rotating ring-disk electrode and the selectivity above $90 \%$ (determined by a colorimetric quantification method) can be maintained at a wide voltage range (Supplementary Fig. 23). Moreover, the intensity of current density at $30 \mathrm{~mA} \mathrm{~cm}^{-2}$ remained unchanged over the course of electrolysis (Fig. 4d, e), which is of great significance for highly efficient $\mathrm{H}_{2} \mathrm{O}_{2}$ generation in practical applications. Within $1 \mathrm{~h}$ at a current density of $30 \mathrm{~mA} \mathrm{~cm}^{-2}, \sim 867 \mathrm{ppm}_{2} \mathrm{O}_{2}$ was generated with an average selectivity of $\sim 92 \%$. As a practical application, we applied the $\mathrm{O}-\mathrm{C}(\mathrm{Al})$ catalyst to paper and pulp bleaching, and simulated the industrial experiment with blue litmus paper. The experiment showed that the produced $\mathrm{H}_{2} \mathrm{O}_{2}$ could almost completely destroy the existing colored material in the blue litmus paper, indicating that this scheme can potentially be applied to industrial applications (inset in Fig. 4e, Supplementary Fig. 24).

\section{Discussion}

In summary, with the guidance of theoretical predictions, we have rationally constructed a series of oxygen-rich carbons with atomically dispersed Lewis acid sites, through the pyrolysis of MIL-53 with different metal clusters. Besides the inherited structural advantages of the MOF, the enriched atomically dispersed octahedral $\mathrm{MO}_{6}$ clusters in MOF-derived $\mathrm{O}-\mathrm{C}(\mathrm{M})$ catalysts significantly improved the selectivity of $\mathrm{O}_{2}$ reduction to $\mathrm{H}_{2} \mathrm{O}_{2}$ by promoting the formation of $* \mathrm{OOH}$ and weakening the binding strength between the formed ${ }^{*} \mathrm{OOH}$ group and the carbon material. As a result, the catalytic performance of $\mathrm{O}-\mathrm{C}(\mathrm{M})$ for reducing $\mathrm{O}_{2}$ to $\mathrm{H}_{2} \mathrm{O}_{2}$ is much higher than that of $\mathrm{O}-\mathrm{C}$ in both alkaline and neutral media. More importantly, the increase in catalytic selectivity correlates well with Lewis acidity, following a nearly linear correlation. We envision that the current strategy, on forming atomically dispersed Lewis acid sites on the carbon matrix, can open an avenue to fabricate important highperformance future catalysts for 2-electron ORR and other similar processes.

\section{Methods}

Materials and characterization. All chemicals were obtained from commercial suppliers at analytical grade and used as received without further purification. $\mathrm{Al}$ $\left(\mathrm{NO}_{3}\right)_{3} \cdot 9 \mathrm{H}_{2} \mathrm{O}, \mathrm{Ga}\left(\mathrm{NO}_{3}\right)_{3} \cdot x \mathrm{H}_{2} \mathrm{O}, \mathrm{Cr}\left(\mathrm{NO}_{3}\right)_{3} \cdot 9 \mathrm{H}_{2} \mathrm{O}$, aqueous HF, melamine, 1,10 phenanthroline, sulfur powder were obtained from Shanghai Aladdin Bio-Chem Technology Co., LTD. 1,4-benzene dicarboxylic acid was obtained from TCI Shanghai. Nafion solution was obtained from Sigma-Aldrich. Power X-ray diffractions (PXRD) patterns of the samples were collected on a D8-Advance Bruker AXS diffractometer with $\mathrm{Cu} k \alpha(\lambda=1.5418 \AA)$ radiation at room temperature. Inductively coupled plasma mass spectroscopy (ICP-MS) measurements were carried on NexION 300 (PerkinElmer). The samples' morphologies were examined using a field emission scanning electron microscope (SEM, Hitachi, S-4800). Transmission electron microscopy (TEM) images were recorded on Tecnai F20 microscope. The aberration-corrected HAADF-STEM measurements were taken on a JEM-ARM200F instrument at $200 \mathrm{keV}$. X-ray photoelectron spectroscopy (XPS) measurements were performed by using a thermo ESCALAB 250 high-performance electron spectrometer using monochromatized $\mathrm{Al} \mathrm{Ka}(h v=1486.6 \mathrm{eV})$ as the excitation source. Al K-edge X-ray absorption spectroscopy (XAS) was conducted at beamline 02B02 of the SiP.ME2 platform at the Shanghai Synchrotron Radiation Facility (SSRF).

Preparation of MIL-53(Al). MIL-53(Al) was synthesized and purified according to the reported procedures ${ }^{33}$. A typical synthesis involves a solution containing $\mathrm{Al}$ $\left(\mathrm{NO}_{3}\right)_{3} \cdot 9 \mathrm{H}_{2} \mathrm{O}(1.3 \mathrm{~g}), 1,4$-benzene dicarboxylic acid $(0.288 \mathrm{~g})$, de-ionized water $(5 \mathrm{~mL})$. The mixture was introduced into a Teflon-lined autoclave and heated for $3 \mathrm{~d}$ at $220^{\circ} \mathrm{C}$ in an oven under static condition. The obtained MIL-53(Al) was purified twice by in ethanol at reflux temperature for $12 \mathrm{~h}$ and washed with hot ethanol. The sample was finally dried at $60^{\circ} \mathrm{C}$ for $12 \mathrm{~h}$ under a dynamic vacuum prior to further use. 
Preparation of MIL-53(Ga). MIL-53(Ga) was synthesized and purified according to the reported procedures ${ }^{34}$. A typical synthesis involves a solution containing Ga $\left(\mathrm{NO}_{3}\right)_{3} \cdot x \mathrm{H}_{2} \mathrm{O}(1.0 \mathrm{~g}), 1,4$-benzene dicarboxylic acid $(0.76 \mathrm{~g})$, de-ionized water $(20 \mathrm{~mL})$. The mixture was introduced into a Teflon-lined autoclave and heated for $4 \mathrm{~h}$ at $210^{\circ} \mathrm{C}$ in an oven under static condition. The obtained MIL-53(Ga) was purified twice by in ethanol at reflux temperature for $12 \mathrm{~h}$ and washed with hot ethanol. The sample was finally dried at $60^{\circ} \mathrm{C}$ for $12 \mathrm{~h}$ under a dynamic vacuum prior to further use.

Preparation of MIL-53(Cr). MIL-53(Cr) was synthesized and purified according to the reported procedures ${ }^{35}$. A typical synthesis involves a solution containing $\mathrm{Cr}$ $\left(\mathrm{NO}_{3}\right)_{3} \cdot 9 \mathrm{H}_{2} \mathrm{O}(1.384 \mathrm{~g}), 1,4$-benzene dicarboxylic acid $(0.575 \mathrm{~g})$, de-ionized water $(24 \mathrm{~mL})$, aqueous $\mathrm{HF}(0.14 \mathrm{~mL})$. The mixture was introduced into a Teflon-lined autoclave and heated for $3 \mathrm{~d}$ at $220^{\circ} \mathrm{C}$ in an oven under static condition. The obtained MIL-53(Cr) was purified twice by in ethanol at reflux temperature for $12 \mathrm{~h}$ and washed with hot ethanol. The sample was finally dried at $60^{\circ} \mathrm{C}$ for $12 \mathrm{~h}$ under a dynamic vacuum prior to further use.

Preparation of O-C. Typically, $600 \mathrm{mg}$ 1,4-benzene dicarboxylic acid was mixed with $30 \mathrm{mg}$ carbon black and ground at room temperature for $1 \mathrm{~h}$. Then the mixture was placed in a porcelain boat with a cap and charged into a flow-through tube furnace. The furnace was heated to $800^{\circ} \mathrm{C}$ under a nitrogen atmosphere with a flow rate of $60 \mathrm{~mL} \mathrm{~min}^{-1}$, and then maintained at the target temperature for $2 \mathrm{~h}$, followed by cooling down to room temperature in a nitrogen atmosphere.

Preparation of O-C(M) (M = Al, Ga, Cr). Typically, $600 \mathrm{mg}$ MIL-53(Al, Ga, Cr) was placed in a porcelain boat and charged into a flow-through tube furnace. The furnace was heated to $800^{\circ} \mathrm{C}$ under a nitrogen atmosphere with a flow rate of $60 \mathrm{~mL} \mathrm{~min}^{-1}$, and then maintained at the target temperature for $2 \mathrm{~h}$, followed by cooling down to room temperature in a nitrogen atmosphere. The obtained solid was immersed in $10 \mathrm{~mL}$ aqueous solution of $\mathrm{NaOH}(0.1 \mathrm{M})$ and $1 \mathrm{~mL}$ ethanol with continued shaking at room temperature for $12 \mathrm{~h}$. The final product was collected by centrifugation and washed 3 times with ethanol.

Preparation of N-C. Typically, $2 \mathrm{~g}$ melamine and $50 \mathrm{mg}$ carbon black were mixed with $2 \mathrm{~mL}$ ethanol solution of 1,10 -phenanthroline $(0.6 \mathrm{mmol})$ and $2 \mathrm{~mL} \mathrm{H}_{2} \mathrm{O}$, then the mixture was ground at room temperature for $1 \mathrm{~h}$ and then dried at $60^{\circ} \mathrm{C}$ for $2 \mathrm{~h}$ under vacuum. The obtained solid was pyrolyzed at $600^{\circ} \mathrm{C}$ for $2 \mathrm{~h}$ under a nitrogen atmosphere with a flow rate of $60 \mathrm{~mL} \mathrm{~min}{ }^{-1}$. Finally, the resultant composite was placed in a porcelain boat with a cap and charged into a flow-through tube furnace. The furnace was heated to $800^{\circ} \mathrm{C}$ under a nitrogen atmosphere with a flow rate of $60 \mathrm{~mL} \mathrm{~min}^{-1}$, and then maintained at the target temperature for $2 \mathrm{~h}$, followed by cooling down to room temperature in a nitrogen atmosphere.

Preparation of $\mathbf{N}-\mathbf{C}(\mathbf{M})(\mathbf{M}=\mathbf{A l}, \mathbf{G a})$. Typically, $2 \mathrm{~g}$ melamine was mixed with $2 \mathrm{~mL}$ ethanol solution of 1,10 -phenanthroline $(0.6 \mathrm{mmol})$ and $2 \mathrm{~mL}$ aqueous solution of $\mathrm{Al}\left(\mathrm{NO}_{3}\right)_{3}$ or $\mathrm{Ga}\left(\mathrm{NO}_{3}\right)_{3}(0.2 \mathrm{mmol})$, then the mixture was ground at room temperature for $1 \mathrm{~h}$ and then dried at $60^{\circ} \mathrm{C}$ for $2 \mathrm{~h}$ under vacuum. The obtained solid was pyrolyzed at $600^{\circ} \mathrm{C}$ for $2 \mathrm{~h}$ under a nitrogen atmosphere with a flow rate of $60 \mathrm{~mL} \mathrm{~min}{ }^{-1}$. Finally, the resultant composite was placed in a porcelain boat with a cap and charged into a flow-through tube furnace. The furnace was heated to $800^{\circ} \mathrm{C}$ under a nitrogen atmosphere with a flow rate of $60 \mathrm{~mL} \mathrm{~min}{ }^{-1}$, and then maintained at the target temperature for $2 \mathrm{~h}$, followed by cooling down to room temperature in a nitrogen atmosphere.

Preparation of S-C. First, $1 \mathrm{~g}$ carbon black was immersed in $40 \mathrm{~mL}$ aqueous solution of $\mathrm{HCl}(6 \mathrm{M})$ with continued to stir at $100^{\circ} \mathrm{C}$ for $24 \mathrm{~h}$, and the solid was washed three times with de-ionized water to remove all the possible residual acid. Then the solid was mixed with $20 \mathrm{~g}$ sulfur powder and ground at room temperature for $1 \mathrm{~h}$. Finally, the mixture was placed in a porcelain boat with a cap and charged into a flow-through tube furnace. The furnace was heated to $800{ }^{\circ} \mathrm{C}$ under a nitrogen atmosphere with a flow rate of $60 \mathrm{~mL} \mathrm{~min}^{-1}$, and then maintained at the target temperature for $2 \mathrm{~h}$, followed by cooling down to room temperature in a nitrogen atmosphere.

Preparation of S-C(M) (M $=\mathbf{A l}, \mathbf{G a})$. Typically, $200 \mathrm{mg} \mathrm{S-C}$ was mixed with $1 \mathrm{~mL}$ aqueous solution of $\mathrm{Al}\left(\mathrm{NO}_{3}\right)_{3}$ or $\mathrm{Ga}\left(\mathrm{NO}_{3}\right)_{3}(0.43 \mathrm{mmol})$, then the mixture was ground at room temperature for $1 \mathrm{~h}$ and then dried at $60^{\circ} \mathrm{C}$ for $2 \mathrm{~h}$ under vacuum. The obtained solid was placed in a porcelain boat with a cap and charged into a flow-through tube furnace. The furnace was heated to $800^{\circ} \mathrm{C}$ under a nitrogen atmosphere with a flow rate of $60 \mathrm{~mL} \mathrm{~min}^{-1}$, and then maintained at the target temperature for $2 \mathrm{~h}$, followed by cooling down to room temperature in a nitrogen atmosphere.

DFT calculation. Density functional theory was performed with the Vienna ab initio simulation package (VASP) ${ }^{53}$. The ion-electron interaction was described by employing the projector augmented wave (PAW) method ${ }^{54}$. The exchange- correlation energy functional was described by the generalized gradient approximation (GGA) in the Perdew-Burke-Ernzerhof (PBE) functional ${ }^{55}$. The kinetic cutoff energy for the plane wave was set as $450 \mathrm{eV}$ for all computational calculations. The convergence criteria for each atom were set to be $1 \mathrm{E}-5 \mathrm{eV}$ for residual energy and $0.03 \mathrm{eV}^{-1}$ for force. A $5 \times 5 \times 1$ supercell of the graphene was employed as the simulation model. The vacuum space was $20 \AA$ to avoid artificial interactions between periodic images. The k-points in the Brillouin zone were sampled by a $3 \times 3 \times 1$ grid. The DFT-D3 method was used to describe the van der Waals (vdW) interactions between the adsorbed species and the catalyst. All the studied models are shown in Fig. 1 and Supplementary Fig. 1a, and the structures of the two possible reaction pathways are depicted in Supplementary Fig. 1b.

The computational hydrogen electrode (CHE) mode ${ }^{56}$ was used to calculate the Gibbs reaction-free energy change $(\Delta G)$ for each step in the two-electron oxygen reduction reaction (ORR). According to the CHE model, the $\Delta G$ value was gained by Eq. (3):

$$
\Delta G=\Delta E_{\mathrm{DFT}}+\Delta E_{\mathrm{ZPE}}-T \Delta S+e U+\Delta G_{\mathrm{pH}},
$$

where $\Delta E_{\mathrm{DFT}}$ is the reaction energy, $\Delta_{\mathrm{ZPE}}$ and $\Delta S$ are the changes in zero-point energy and entropy at $298.15 \mathrm{k}$, respectively. $T, e$, and $U$ are the temperature, the number of electrons transferred and the electrode potential, respectively. The $\Delta G_{\mathrm{pH}}$ is the free energy correction of $\mathrm{pH}$, which can be calculated by Eq. (4):

$$
\Delta G_{\mathrm{pH}}=\ln 10 \times k_{\mathrm{B}} T \times \mathrm{pH} .
$$

The $k_{\mathrm{B}}$ is the Boltzman constant. Since RHE is taken as the reference, the $\mathrm{pH}$ was set to be zero in this calculation. The limiting potential $\left(U_{\mathrm{L}}\right)$ is defined as the lowest potential as at which all the reaction steps are downhill in free energy.

The total energy $(E)$ and corresponding thermodynamic quantities, in $\mathrm{eV}$, for free $\mathrm{H}_{2}, \mathrm{H}_{2} \mathrm{O}, \mathrm{H}_{2} \mathrm{O}_{2}$ species, were listed in Supplementary Table $8^{39}$. Since $\mathrm{O}_{2}$ molecule is poorly described by standard DFT calculations, all the free energies were calculated by using the free energies of $\mathrm{H}_{2} \mathrm{O}(\mathrm{l})$ and $\mathrm{H}_{2}(\mathrm{~g})$ as ref. ${ }^{30}$. The free energies of $\mathrm{O}_{2}$ molecule and $\mathrm{H}_{2} \mathrm{O}_{2}$ molecules are determined by equilibrium potential of four-electron (1.23 V vs. RHE) and two-electron (0.70 V vs. RHE) ORR, which are estimated by $4.92(4 \times 1.23)$ and $3.52(4 \times 1.23-0.70 \times 2) \mathrm{eV}$, respectively.

For the two-electron ORR, there are two reaction steps ${ }^{25}$ :

$$
\begin{aligned}
& *+\mathrm{O}_{2}+\mathrm{H}^{+}+e^{-} \rightarrow{ }^{*} \mathrm{OOH}, \\
& * \mathrm{OOH}+\mathrm{H}^{+}+e^{-} \rightarrow \mathrm{H}_{2} \mathrm{O}_{2}+*
\end{aligned}
$$
(9):

For the hydrogenation of oxygen (Eq. (5)), the $\Delta G$ was calculated by Eqs. (7)-

$$
\begin{gathered}
\Delta G_{1}=G\left({ }^{*} \mathrm{OOH}\right)-G\left({ }^{*}\right)-G\left(\mathrm{O}_{2}\right)-0.5 \times G\left(\mathrm{H}_{2}\right), \\
\Delta G_{1}=G\left({ }^{*} \mathrm{OOH}\right)-G\left({ }^{*}\right)-\left(4.92-2 \times G\left(\mathrm{H}_{2}\right)+2 \times G\left(\mathrm{H}_{2} \mathrm{O}\right)\right)-0.5 \times G\left(\mathrm{H}_{2}\right),
\end{gathered}
$$

$$
\Delta G_{1}=G\left({ }^{*} \mathrm{OOH}\right)-G(*)-4.92+1.5 \times G\left(\mathrm{H}_{2}\right)-2 \times G\left(\mathrm{H}_{2} \mathrm{O}\right),
$$

while for the reduction of $\mathrm{OOH}^{*}$ to from $\mathrm{H}_{2} \mathrm{O}_{2}$ (Eq. (6)), the $\Delta G$ can be obtained directly by Eq. (10):

$$
\Delta G_{2}=-1.40 \mathrm{eV}-\Delta G_{1},
$$

herein, the $G\left({ }^{*} \mathrm{OOH}\right)$ is defined by Eq. (11):

$$
G\left({ }^{*} \mathrm{OOH}\right)=4.92 \mathrm{eV}+\Delta G_{1} .
$$

The ORR activity and selectivity evaluated over a rotating ring-disk electrode. In general, the electrodes were prepared by dispersing the $3.3 \mathrm{mg}$ catalyst and $30 \mu \mathrm{L}$ Nafion in $1 \mathrm{~mL}$ ethanol. After sonication for $2 \mathrm{~h}, 6 \mu \mathrm{L}$ of the catalyst ink was dropdried onto a glassy carbon disk (area: $0.2475 \mathrm{~cm}^{2}$ ). The electrochemical tests were performed in a computer-controlled potentiostat (CHI-Instrument) with a fourelectrode cell at room temperature. The rotating ring-disk electrode loaded with catalyst was used as the working electrode. A graphite rod and a saturated $\mathrm{Ag} / \mathrm{AgCl}$ electrode were used as the counter and a reference electrode, respectively. Two electrolytes with $\mathrm{pH} \sim 13(0.1 \mathrm{M} \mathrm{NaOH})$ and $\sim 7(0.1 \mathrm{M}$ phosphate-buffered saline and $0.5 \mathrm{M} \mathrm{Na}_{2} \mathrm{SO}_{4}$ ) were chosen. The ORR activity and selectivity were investigated by polarization curves and rotating ring-disk electrode measurements in oxygen saturated electrolyte at a scan rate of $10-20 \mathrm{mV} \mathrm{s}^{-1}$. A potential of $1.2 \mathrm{~V}$ (vs. RHE) was applied to the ring of the working electrode during the entire testing process.

$\mathrm{H}_{2} \mathrm{O}_{2}$ selectivity of catalysts on the rotating ring-disk electrode was calculated based on the current of the disk electrode and ring electrode. The expression is as Eq. (12):

$$
\text { Sel. }(\%)=2 \times \frac{I_{\mathrm{R}} / N}{I_{\mathrm{D}}+I_{\mathrm{R}} / N},
$$

$I_{\mathrm{R}}$ : the ring current, $I_{\mathrm{D}}$ : the disk current, $N$ : the collection efficiency $(0.35$ after calibration). 
The ORR activity and selectivity evaluated over a $\mathbf{H}$-cell system. In general, electrocatalytic $\mathrm{H}_{2} \mathrm{O}_{2}$ production on Teflon-treated carbon fiber paper loaded with catalysts $\left(1 \mathrm{mg} \mathrm{cm}{ }^{-2}\right)$ was performed in a two-compartment cell with Nafion 117 membrane as a separator. Both the cathode compartment $(20 \mathrm{~mL})$ and anode compartment were filled with the same electrolyte. The $\mathrm{H}_{2} \mathrm{O}_{2}$ concentration was measured by a traditional titration method based on the mechanism that a colorless solution of $\mathrm{Ti}\left(\mathrm{SO}_{4}\right)_{2}$ would be oxidized by $\mathrm{H}_{2} \mathrm{O}_{2}$ to $\mathrm{H}_{2} \mathrm{TiO}_{4}$ with yellow color (Eq. (13)).

$$
\mathrm{Ti}^{4+}+\mathrm{H}_{2} \mathrm{O}_{2}+2 \mathrm{H}_{2} \mathrm{O} \rightarrow \mathrm{H}_{2} \mathrm{TiO}_{4}+4 \mathrm{H}^{+} \text {. }
$$

Thus, the concentration of $\mathrm{H}_{2} \mathrm{O}_{2}$ after the reaction can be measured by UV-Vis spectroscopy. The wavelength used for the measurement of $\mathrm{H}_{2} \mathrm{TiO}_{4}$ was $408 \mathrm{~nm}$.

The theoretical amount of $\mathrm{H}_{2} \mathrm{O}_{2}$ in $20 \mathrm{~mL}$ solution can be calculated via the consumed quantity of electric charge within the electrocatalysis. The expression is as Eq. (14):

$$
\begin{aligned}
C & =\frac{Q \times M}{2 \times \mathrm{NA} \times Q_{\mathrm{e}} \times V}=8.82 \mathrm{ppm} \\
& =\frac{1 C \times 34 \mathrm{~g} \mathrm{~mol}^{-1}}{2 \times 6.02 \times 10^{23} \mathrm{e} \mathrm{mol}^{-1} \times 1.60 \times 10^{-19} \mathrm{C} \mathrm{e}^{-1} \times 20 \mathrm{~mL}}
\end{aligned}
$$

NA: Avogadro constant $\left(6.02 \times 10^{23} \mathrm{e} \mathrm{mol}^{-1}\right)$; Q: quantity of electric charge (C); $M$ : relative molecular mass of $\mathrm{H}_{2} \mathrm{O}_{2}\left(34 \mathrm{~g} \mathrm{~mol}^{-1}\right) ; V$ : the volume of the solution $(20 \mathrm{~mL}) ; C$ : the concentration of $\mathrm{H}_{2} \mathrm{O}_{2}\left(\mathrm{~g} \cdot \mathrm{mL}^{-1}\right)$; $Q_{\mathrm{e}}$ : the quantity of electric charge for each electron $\left(1.60 \times 10^{-19} \mathrm{C} \cdot \mathrm{e}^{-1}\right)$.

\section{Data availability}

The data that support the findings of this study are available from the corresponding author upon reasonable request.

Received: 19 March 2020; Accepted: 6 October 2020;

Published online: 30 October 2020

\section{References}

1. Brillas, E., Sires, I. \& Oturan, M. A. Electro-Fenton process and related electrochemical technologies based on Fenton's reaction chemistry. Chem. Rev. 109, 6570-6631 (2009).

2. Hage, R. \& Lienke, A. Applications of transition-metal catalysts to textile and wood-pulp bleaching. Angew. Chem. Int. Ed. 45, 206-222 (2006).

3. Yang, S. et al. Toward the decentralized electrochemical production of $\mathrm{H}_{2} \mathrm{O}_{2}$ : a focus on the catalysis. ACS Catal. 8, 4064-4081 (2018).

4. Kim, H. W. et al. Efficient hydrogen peroxide generation using reduced graphene oxide-based oxygen reduction electrocatalysts. Nat. Catal. 1 , 282-290 (2018).

5. Campos-Martin, J. M., Blanco-Brieva, G. \& Fierro, J. L. G. Hydrogen peroxide synthesis: an outlook beyond the anthraquinone process. Angew. Chem. Int. Ed. 45, 6962-6984 (2006).

6. Xia, C., Xia, Y., Zhu, P., Fan, L. \& Wang, H. T. Direct electrosynthesis of pure aqueous $\mathrm{H}_{2} \mathrm{O}_{2}$ solutions up to $20 \%$ by weight using a solid electrolyte. Science 366, 226-231 (2019).

7. Jirkovsky, J. S. et al. Single atom hot-spots at Au-Pd nanoalloys for electrocatalytic $\mathrm{H}_{2} \mathrm{O}_{2}$ production. J. Am. Chem. Soc. 133, 19432-19441 (2011).

8. Verdaguer-Casadevall, A. et al. Trends in the electrochemical synthesis of $\mathrm{H}_{2} \mathrm{O}_{2}$ : enhancing activity and selectivity by electrocatalytic site engineering. Nano Lett. 14, 1603-1608 (2014).

9. Edwards, J. K. et al. Switching off hydrogen peroxide hydrogenation in the direct synthesis process. Science 323, 1037-1041 (2009).

10. Shen, R. G. et al. High-concentration single atomic Pt sites on hollow $\mathrm{CuS}_{\mathrm{x}}$ for selective $\mathrm{O}_{2}$ reduction to $\mathrm{H}_{2} \mathrm{O}_{2}$ in acid solution. Chem 5, 2099-2110 (2019).

11. Jiang, Y. Y. et al. Selective electrochemical $\mathrm{H}_{2} \mathrm{O}_{2}$ production through twoelectron oxygen electrochemistry. Adv. Energy Mater. 8, 1801909 (2018).

12. Cheon, J. Y. et al. Intrinsic relationship between enhanced oxygen reduction reaction activity and nanoscale work function of doped carbons. J. Am. Chem. Soc. 136, 8875-8878 (2014).

13. Choi, C. H. et al. The achilles' heel of iron-based catalysts during oxygen reduction in an acidic medium. Energy Environ. Sci. 11, 3176-3182 (2018).

14. Perry, S. C. et al. Electrochemical synthesis of hydrogen peroxide from water and oxygen. Nat. Rev. Chem. 3, 442-458 (2019).

15. Kim, J. H., Kim, Y.-T. \& Joo, S. H. Electrocatalyst design for promoting twoelectron oxygen reduction reaction: Isolation of active site atoms. Curr. Op. Electrochem. 21, 109-116 (2020)
16. Liu, Y., Quan, X., Fan, X., Wang, H. \& Chen, S. High-yield electrosynthesis of hydrogen peroxide from oxygen reduction by hierarchically porous carbon. Angew. Chem. Int. Ed. 54, 6837-6841 (2015).

17. Lglesias, $\mathrm{D}$. et al. $\mathrm{N}$-doped graphitized carbon nanohorns as a forefront electrocatalyst in highly selective $\mathrm{O}_{2}$ reduction to $\mathrm{H}_{2} \mathrm{O}_{2}$. Chem 4, 106-123 (2018).

18. Sa, Y. J., Kim, J. H. \& Joo, S. H. Active edge-site-rich carbon nanocatalysts with enhanced electron transfer for efficient electrochemical hydrogen peroxide production. Angew. Chem. Int. Ed. 58, 1100-1105 (2019).

19. Yang, S., Kim, J., Tak, Y. J., Soon, A. \& Lee, H. Single-atom catalyst of platinum supported on titanium nitride for selective electrochemical reactions. Angew. Chem. Int. Ed. 55, 2058-2062 (2016).

20. Ko, M. et al. Unassisted solar lignin valorisation using a compartmented photo-electro-biochemical cell. Nat. Commun. 10, 5123 (2019).

21. Kim, J. H. et al. A general strategy to atomically dispersed precious metal catalysts for unravelling their catalytic trends for oxygen reduction. ACS Nano 14, 1990-2001 (2020).

22. Shao, M. H., Chang, Q. W., Dodelet, J. P. \& Chenitz, R. Recent advances in electrocatalysts for oxygen reduction reaction. Chem. Rev. 116, 3594-3657 (2016).

23. Siahrostami, S. et al. Enabling direct $\mathrm{H}_{2} \mathrm{O}_{2}$ production through rational electrocatalyst design. Nat. Mater. 12, 1137-1143 (2013).

24. Freakley, S. J. et al. Palladium-tin catalysts for the direct synthesis of $\mathrm{H}_{2} \mathrm{O}_{2}$ with high selectivity. Science 351, 965-968 (2016).

25. Lu, Z. Y. et al. High-efficiency oxygen reduction to hydrogen peroxide catalysed by oxidized carbon materials. Nat. Catal. 1, 156-162 (2018).

26. Fellinger, T. P., Hasche, F., Strasser, P. \& Antonietti, M. Mesoporous nitrogendoped carbon for the electrocatalytic synthesis of hydrogen peroxide. J. Am. Chem. Soc. 134, 4072-4075 (2012).

27. Perazzolo, V. et al. Nitrogen and sulfur doped mesoporous carbon as metalfree electrocatalysts for the in situ production of hydrogen peroxide. Carbon 95, 949-963 (2015).

28. Park, J., Nabae, Y., Hayakawa, T. \& Kakimoto, M. A. Highly selective twoelectron oxygen reduction catalyzed by mesoporous nitrogen-doped carbon. ACS Catal. 4, 3749-3754 (2014)

29. Sun, Y. Y. et al. Activity-selectivity trends in the electrochemical production of hydrogen peroxide over single-site metal-nitrogen-carbon catalysts. J. Am. Chem. Soc. 141, 12372-12381 (2019).

30. Jiang, K. et al. Highly selective oxygen reduction to hydrogen peroxide on transition metal single atom coordination. Nat. Commun. 10, 3997 (2019)

31. Choi, C. H. et al. Tuning selectivity of electrochemical reactions by atomically dispersed platinum catalyst. Nat. Commun. 7, 10922 (2016).

32. Jung, E. et al. Atomic-level tuning of Co-N-C catalyst for high-performance electrochemical $\mathrm{H}_{2} \mathrm{O}_{2}$ production. Nat. Mater. 19, 436-442 (2020).

33. Ferey, G. et al. Hydrogen adsorption in the nanoporous metalbenzenedicarboxylate $\mathrm{M}(\mathrm{OH})\left(\mathrm{O}_{2} \mathrm{C}-\mathrm{C}_{6} \mathrm{H}_{4}-\mathrm{CO}_{2}\right)\left(\mathrm{M}=\mathrm{Al}^{3+}, \mathrm{Cr}^{3+}\right)$, MIL-53. Chem. Commun. 24, 2976-2977 (2003).

34. Volkringer C. et al. XRD and IR structural investigations of a particular breathing effect in the MOF-type gallium terephthalate MIL-53(Ga). Dalton Trans. 12, 2241-2249 (2009).

35. Serre, C. et al. Very large breathing effect in the first nanoporous chromium (III)-based solids: MIL-53 or $\mathrm{Cr}^{\mathrm{III}}(\mathrm{OH}) \cdot\left\{\mathrm{O}_{2} \mathrm{C}-\mathrm{C}_{6} \mathrm{H}_{4}-\mathrm{CO}_{2}\right\} \cdot\left\{\mathrm{HO}_{2} \mathrm{C}-\mathrm{C}_{6} \mathrm{H}_{4}\right.$ $\left.\mathrm{CO}_{2} \mathrm{H}\right\}(\mathrm{x}) \cdot \mathrm{H}_{2} \mathrm{O}_{\mathrm{y}}$. J. Am. Chem. Soc. 124, 13519-13526 (2002).

36. Freund H. J. \& Umbach E. Adsorption on Ordered Surfaces of Ionic Solids and Thin Films (Springer-Verlag, Berlin, 1993).

37. $\mathrm{Gu}, \mathrm{Q}$. Q. et al. Probing the intrinsic catalytic activity of carbon nanotubes for the metal-free oxidation of aromatic thiophene compounds in ionic liquids. J. Energy Chem. 32, 131-137 (2019).

38. Man, I. C. et al. Universality in oxygen evolution electrocatalysis on oxide surfaces. ChemCatChem 3, 1159-1165 (2011).

39. Guo, X. et al. Simultaneously achieving high activity and selectivity toward two electron $\mathrm{O}_{2}$ electroreduction: the power of single-atom catalysts. ACS Catal. 9, 11042-11054 (2019).

40. Carey F. A. \& Sundberg R. J. Advanced Organic Chemistry: Part A: Structure and Mechanisms (Springer-Verlag, Berlin, 2007).

41. Gong, K. P., Du, F., Xia, Z. H., Durstock, M. \& Dai, L. M. Nitrogen-doped carbon nanotube arrays with high electrocatalytic activity for oxygen reduction. Science 323, 760-764 (2009).

42. Sakuragi, N., Yamamoto, S. \& Koide, Y. A self-assembled monolayers assisted solid-state conversion of boehmite particles to aluminum oxide film. J. Am. Chem. Soc. 129, 10048-10049 (2007).

43. Williams, G., Wang, Q. \& Aziz, H. The photo-stability of polymer solar cells: contact photo-degradation and the benefits of interfacial layers. Adv. Funct. Mater. 23, 2239-2247 (2013).

44. Fyfe, C. A., Bretherton, J. L., Lam, L. Y. \& Solid-state, N. M. R. detection, characterization, and quantification of the multiple aluminum environments in US-Y catalysts by Al-27 MAS and MQMAS experiments at very high field. J. Am. Chem. Soc. 123, 5285-5291 (2001). 
45. Mckeown, D. A., Waychunas, G. A. \& Brown, G. E. Exafs study of the coordination environment of aluminum in a series of silica-rich glasses and selected minerals within the $\mathrm{Na}_{2} \mathrm{O}-\mathrm{Al}_{2} \mathrm{O}_{3}-\mathrm{SiO}_{2}$ system. J. Non-Cryst. Solids 74, 349-371 (1985).

46. Choi, C. H. et al. Unraveling the nature of sites active toward hydrogen peroxide reduction in Fe-N-C catalysts. Angew. Chem. Int. Ed. 56, 8809-8812 (2017).

47. Wang, X. X. et al. Nitrogen-coordinated single cobalt atom catalysts for oxygen reduction in proton exchange membrane fuel cells. Adv. Mater. 30, 1706758 (2018).

48. Li, B. Q., Zhao, C. X., Liu, J. N. \& Zhang, Q. Electrosynthesis of hydrogen peroxide synergistically catalyzed by atomic $\mathrm{Co}-\mathrm{N}_{\mathrm{x}}-\mathrm{C}$ sites and oxygen functional groups in noble-metal-free electrocatalysts. Adv. Mater. 31, 1808173 (2019).

49. Chen, Y. Z. et al. Multifunctional PdAg@MIL-101 for one-pot cascade reactions: combination of host-guest cooperation and bimetallic synergy in catalysis. ACS Catal. 5, 2062-2069 (2015).

50. Turco, M. et al. Production of hydrogen from oxidative steam reforming of methanol: I. preparation and characterization of $\mathrm{Cu} / \mathrm{ZnO} / \mathrm{Al}_{2} \mathrm{O}_{3}$ catalysts from a hydrotalcite-like LDH precursor. J. Catal. 228, 43-55 (2004).

51. Neumann, G. T. \& Hicks, J. C. Novel hierarchical cerium-incorporated MFI zeolite catalysts for the catalytic fast pyrolysis of lignocellulosic biomass. ACS Catal. 2, 642-646 (2012).

52. Ding, M. \& Jiang, H.-L. Incorporation of imidazolium-based poly(ionic liquid) $s$ into a metal-organic framework for $\mathrm{CO}_{2}$ capture and conversion. ACS Catal. 8, 3194-3201 (2018).

53. Kresse, G. \& Furthmuller, J. Efficient iterative schemes for ab initio total-energy calculations using a plane-wave basis set. Phys. Rev. B 54, 11169-11186 (1996).

54. Kresse, G. \& Joubert, D. From ultrasoft pseudopotentials to the projector augmented-wave method. Phys. Rev. B 59, 1758-1775 (1999)

55. Perdew, J. P., Burke, K. \& Ernzerhof, M. Generalized gradient approximation made simple. Phys. Rev. Lett. 77, 3865-3868 (1996).

56. Norskov, J. K. et al. Origin of the overpotential for oxygen reduction at a fuelcell cathode. J. Phys. Chem. B 108, 17886-17892 (2004).

\section{Acknowledgements}

This work is supported by the National Key Research and Development Program of China (No. 2018YFB0704300), National Natural Science Foundation of China (Nos. 21803074 and 51872306), the Science and Technology Innovation 2025 Program in Ningbo (2019B10046), Fujian Institute of Innovation, Chinese Academy of Sciences, the China Postdoctoral Science Foundation (No. 2019M660146), the National Postdoctoral Program for Innovative Talents (Nos. BX20190340 and BX20190339), and Hundred Talents Program in Chinese Academy of Sciences. The DFT calculation is supported by the High-Performance Computing Center of Collaborative Innovation Center of Advanced Microstructures, Nanjing University.

\section{Author contributions}

L.C., Z.L., and Q.Y. designed the project and wrote the manuscript; Q.Y. and W.X. carried out the experiments and collected the data; Z.T., S.G., and G.Z. carried out DFT calculations and wrote the computational part of the manuscript; Y.W. and L.P. carried out the experiments of solid-state NMR; L.Z. performed the XANES and EXAFS experiments and data analysis. All authors discussed the results and commented on the manuscript.

\section{Competing interests}

The authors declare no competing interests.

\section{Additional information}

Supplementary information is available for this paper at https://doi.org/10.1038/s41467020-19309-4.

Correspondence and requests for materials should be addressed to Z.T., Z.L. or L.C.

Peer review information Nature Communications thanks Debra J. Searles and other, anonymous, reviewers for their contributions to the peer review of this work.

Reprints and permission information is available at http://www.nature.com/reprints

Publisher's note Springer Nature remains neutral with regard to jurisdictional claims in published maps and institutional affiliations.

\section{(c) (i)}

Open Access This article is licensed under a Creative Commons Attribution 4.0 International License, which permits use, sharing, adaptation, distribution and reproduction in any medium or format, as long as you give appropriate credit to the original author(s) and the source, provide a link to the Creative Commons license, and indicate if changes were made. The images or other third party material in this article are included in the article's Creative Commons license, unless indicated otherwise in a credit line to the material. If material is not included in the article's Creative Commons license and your intended use is not permitted by statutory regulation or exceeds the permitted use, you will need to obtain permission directly from the copyright holder. To view a copy of this license, visit http://creativecommons.org/ licenses/by/4.0/.

(C) The Author(s) 2020 